\title{
Portopulmonar hypertension: Is there something new?
}

\section{Liz Toapanta-Yanchapaxi', Juan Francisco Sánchez-Ávila', Nielzer Rodríguez-Almendros², José de Jesús Rodrí-} guez-Andoney ${ }^{3}$, José L. Hernández-Oropeza ${ }^{3}$, Víctor Manuel Páez-Zayas', Ignacio García-Juárez ${ }^{*}$

'Gastroenterology Department and Liver Transplant Unit, National Institute of Medical Science and Nutrition Salvador Zubirán, Mexico City, Mexico ${ }^{2}$ Pulmonary hypertension and Right Ventricular Function Department. UMAE Cardiología. Centro Médico Nacional Siglo XXI, Instituto Mexicano del Seguro Social, Mexico City, Mexico

${ }^{3}$ Pulmonary Hypertension Clinic, National Institute of Medical Science and Nutrition Salvador Zubirán, Mexico City, Mexico

Article Info

\section{Article Notes}

Received: April 17, 2017

Accepted: July 28, 2017

\section{*Correspondence:}

Ignacio García-Juárez, National Institute of Medical Science and Nutrition Salvador Zubirán, Gastroenterology Department, Vasco de Quiroga No.15 Col. Sección XVI, Tlalpan, Mexico City. Mexico, CP: 14080; Tel: (+52) - (15554870900 ext 108;

E-mail: drinter77@gmail.com

C 2017 García-Juárez I. This article is distributed under the terms of the Creative Commons Attribution 4.0 International License.

\section{Keywords}

Portopulmonary hypertension

Right heart catheterization

Liver transplantation

Cirrhosis

\section{ABSTRACT}

Portopulmonary hypertension (POPH) is a rare and life-threatening complication in patients with portal hypertension, with a prevalence of 3 $8 \%$. It is characterized by pulmonary arterial hypertension (PAH) and results from obstruction to arterial flow in the pulmonary arterial bed, leading to the progressive deterioration of both the pulmonary circulation due to arterial remodeling and of the heart, as a result of right ventricular failure. Its diagnosis is based on hemodynamic findings based on a mean pulmonary arterial pressure $(\mathrm{mPAP}) \geq 25 \mathrm{mmHg}$, an increase in pulmonary vascular resistance (PVR) > 3 Wood Units or $>240$ dynes $/ \mathrm{s} / \mathrm{cm}^{-5}$, a pulmonary artery occlusion pressure $(\mathrm{PAOP}) \leq 15 \mathrm{mmHg}$ or an elevated transpulmonary gradient (mPAP PAOP: > $12 \mathrm{mmHg}$ ). Right heart catheterization (RHC) should be appropriately interpreted since management and MELD exception criteria depend on it. Although most therapeutic modalities have been inferred from patients with $\mathrm{PAH}$, currently, new treatments are available and also various POPH clinical trials are ongoing, so further research data will soon be available. LT is a pivotal therapeutic option, but LT candidates require careful monitoring before, during and after the procedure.

\section{Introduction}

Patients with liver cirrhosis can develop pulmonary hypertension (PH) (mean pulmonary arterial pressure or mPAP $\geq 25$ mmHgat rest) ${ }^{1}$ due to different causes, such as a hyperdynamic circulatory state, an increase in effective intravascular volume and recurrent pulmonary embolism. Also, many diseases involve both portal and pulmonary vascular beds, and are associated with $\mathrm{PH}$ (antiphospholipid syndrome, connective tissue disease, schistosomiasis, sarcoidosis, chronic hemolytic anemia and human immunodeficiency virus infection) $)^{1,2}$.

Mantz and Craig were the first to describe an association between portal hypertension (PHT) and PH in 19513. Since then, many advances in the understanding of the pathogenesis and diagnosis of POPH as well as in therapeutic research have been made.

Portopulmonary hypertension (POPH) is defined as $\mathrm{PH}$ associated with PHT; specifically, an increased pressure gradient between the portal vein and the inferior vena cava. In PHT a gradient in the hepatic venous pressure $>6 \mathrm{mmHg}$, a trans-splenic pressure $>$ $15 \mathrm{mmHg}$ and/or a portal vein pressure $>21 \mathrm{mmHg}$ is diagnostic ${ }^{4}$, whether or not the hypertension is secondary to liver disease. It is a 
type of precapillary PH and before 1998, it was considered a secondary cause of PH. With time, it was included in the group of primary PH and since Evian, France (1998), it is a permanent member of Group 1 or pulmonary arterial hypertension $(\mathrm{PAH})^{3,5,6}$.

Its importance lies in that it can lead to significant morbidity and mortality, so early diagnosis and treatment are essential to timely referral for orthotopic liver transplantation (LT).

\section{Definition}

POPH is identified by an increase in pulmonary arterial pressure and a bloodstream flow impediment secondary to progressive obstruction of the arterial vascular bed ${ }^{7}$, leading to a step-by-step dysfunction of the right-sided heart.

POPH criteria were described in 2004 by the Task Force on pulmonary-hepatic disorders and were maintained in the International Liver Transplant Society practice guidelines for the hepatopulmonary syndrome and $\mathrm{POPH}^{8-10}$ (Table 1).

It is important to remember that other causes of PAH should be excluded such as high flow states, volume overload, left heart disease, obstructive/restrictive lung disease, chronic thromboembolic pulmonary disease, sleep disorders among others ${ }^{11}$.
POPH is included in Group 1 of the World Health Organization within associated causes of Pulmonary arterial hypertension (PAH) (2013) (Figure 1) ${ }^{2}$; its recognition is important since these patients' survival is dire when compared with other causes listed in the same group ${ }^{5}$.

\section{Epidemiology}

Most patients are diagnosed between the fourth and fifth decade of life, unlike patients with idiopathic pulmonary arterial hypertension (IPAH) $)^{1,12,13}$. However, patients with an extrahepatic cause of PHT tend to be younger than those with liver cirrhosis as the underlying cause of $\mathrm{POPH}^{14}$.

The incidence of POPH is reported as 1 case per 3 million per year, and it is the most common form of $\mathrm{PAH}^{15}$. Its prevalence is 0.5 to $5 \%$ in all patients with $\mathrm{PHT}^{16,17}$. The frequency of patients with POPH and extrahepatic portal hypertension differs according to the analyzed world region, whereby in the Far East, it is 30\% while in Western countries, it is $10 \%{ }^{16,17}$. In the study REVEAL, (Registry to Evaluate Early and Long-term PAH), $4.9 \%$ of patients had $\mathrm{POPH}^{5}$, with a male: female ratio of $1: 1$, but other reports consider POPH to be more frequent in women ${ }^{18-20}$. It is important to acknowledge that the differences in gender predominance depend on the studied population and not on the disease per $\mathrm{se}^{20}$.

\begin{tabular}{|c|c|}
\hline Definition & Criteria \\
\hline Portopulmonary hypertension ${ }^{8-10,27}$ & $\begin{array}{l}\text { a. Mean pulmonary arterial pressure }(\mathrm{mPAP})>25 \mathrm{mmHg} \\
\text { b. Increased pulmonary vascular resistance }(\mathrm{PVR})>3 \mathrm{Wood} \text { units or }>240 \mathrm{dynes} / \mathrm{s} / \mathrm{cm}^{-5} \\
\text { c. Pulmonary arterial wedge pressures }(\mathrm{PAOP})<15 \mathrm{mmHg} \text { or an elevated transpulmonary gradient } \\
\text { (mPAP - PAOP: }>12 \mathrm{mmHg} \text {. }\end{array}$ \\
\hline Classification ${ }^{10}$ & $\begin{array}{l}\text { a. Mild: } \mathrm{mPAP} \geq 25-35 \mathrm{mmHg} \\
\text { b. Moderate: } \mathrm{mPAP} 35-45 \mathrm{mmHg} \\
\text { c. Severe: } \mathrm{mPAP} \geq 45 \mathrm{mmHg}\end{array}$ \\
\hline
\end{tabular}

Portopulmonary hypertension is currently defined as the presence of portal hypertension plus the abovementioned criteria, obtained by right heart catheterization (RHC). Modified from Transplantation 2016;100:1440-52

Table 1: Definition and classification of Portopulmonary hypertension.

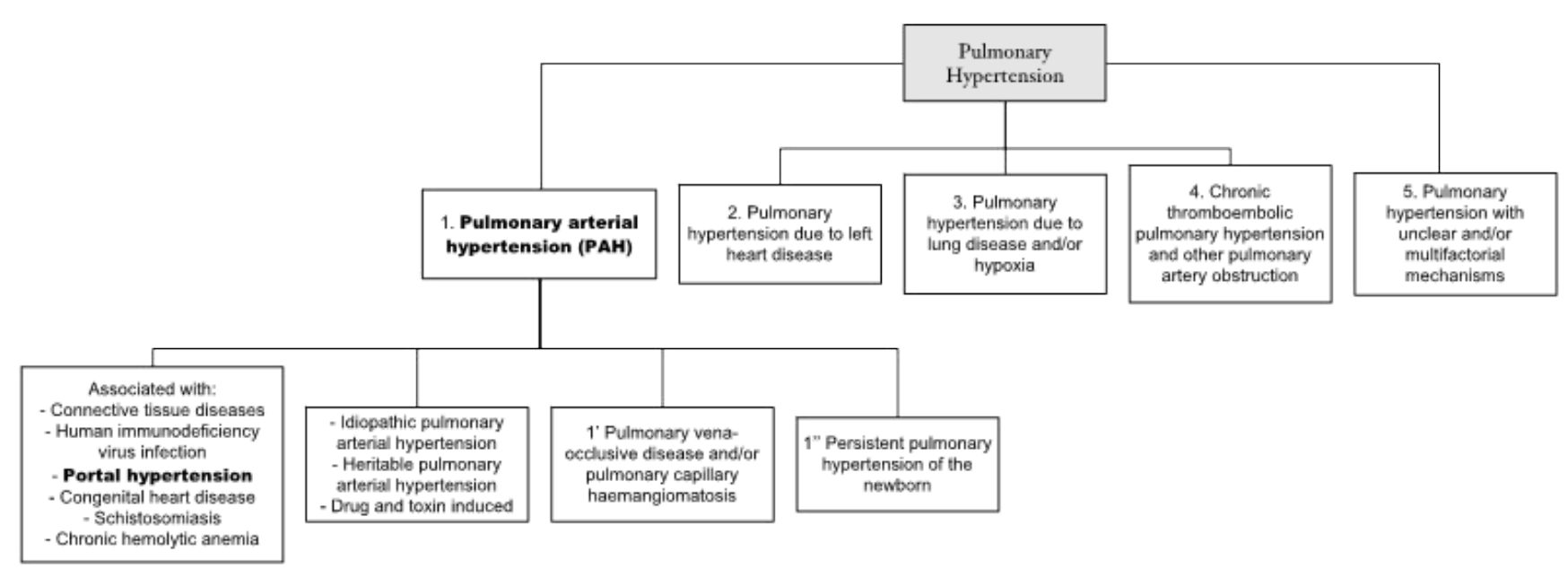

Simplified clinical classification of pulmonary hypertension. (Modified from Eur Heart J 2016;37(1):67-119.)

Figure 1. Clinical classification of pulmonary hypertension. 
The most common etiologies of liver disease associated with POPH are alcohol consumption ${ }^{21}$, hepatitis $C$ virus and an autoimmune etiology $y^{3,18,22}$, while extrahepatic portal hypertension is most commonly the result of portal vein thrombosis ${ }^{21}$ and idiopathic portal hypertension ${ }^{17}$. Some studies have reported that $62.5 \%$ of splenectomized patients and POPH had an underlying autoimmune disease and although no significant difference was noted in Right Heart Catheterization (RHC) values between surgically and non-surgically treated patients, a previous splenectomy could have definite clinical implications ${ }^{22}$. It should be remembered that the presence of POPH correlates poorly with the severity of liver disease according to the Child-Pugh score or Model for End-Stage Liver Disease $(\text { MELD) })^{11,20}$.

The mean time period between the diagnosis of portal hypertension and the overt development of POPH is 4 to 7 years $^{20}$. Clearly, there is no relationship between the severity of the PTH and the degree of PH, but the risk of developing it increases in parallel with the time course of $\mathrm{PTH}^{8,20}$. One of the most important risk factors are portosystemic shunts since vasoactive substances from the splanchnic circulation can be delivered to the pulmonary circulation ${ }^{23}$. Moderate to severe POPH may also correlate with the presence and size of spontaneous splenorenal or portocaval shunts ${ }^{24}$.

In LT candidates, a prevalence of $5.3-8.5 \%$ has been reported ${ }^{11,25,26}$, but notably, up to $5-10 \%$ of patients may have moderate-to-severe POHP which will exclude them from the possibility of $\mathrm{LT}^{27}$. It is necessary to keep in mind that when mPAP is $>35$ but $<50 \mathrm{mmHg}$, RHC is required in the decision-making process (to proceed or not with the LT $)^{28}$. Patients with a pulmonary artery systolic pressure (PSAP) $>50 \mathrm{~mm} \mathrm{Hg}$ on transthoracic echocardiography (TTE), will need hemodynamic corroboration of POPH with right heart (RH) catheterization (RHC) in at least $65 \%$ of cases $^{11 .}$ If patients are treated (with epoprostenol infusion, inhaled iloprost, ambrisentan or sildenafil), hemodynamic criteria allowing LT without excessive cardiovascular mortality can be fulfilled in $70 \%$ of patients ${ }^{29}$.

POPH entails a high mortality, with a reported 1-year survival of $35-46 \%$ if left untreated ${ }^{30,31}$, and a median survival of 15 months $^{32}$. Recently, in a UK publication analyzing different eras, $1992-2002$ vs. $2002-2012$, a $60 \%$ mortality rate vs. $27 \%$ was reported with an associated $53.8 \%$ 5-year survival; ${ }^{32}$ other authors have reported survival rates of $85 \%, 60 \%$ and $35 \%$ at 1 -, 3 - and 5 -years ${ }^{19}$. Mortality can be associated with complications of cirrhosis (up to 33\%), RH failure (in 35\%), a low cardiac index, low central venous saturation and lack of treatment ${ }^{21,33,34}$. With adequate treatment and LT, survival can be increased to $80 \%, 77 \%$ and $77 \%$ at 6 -months, one-year and three-years, respectively ${ }^{29}$.

\section{Classification}

Since 2009, the hemodynamic diagnosis of precapillary $\mathrm{PH}$ hinges on a mPAP $\geq 25 \mathrm{~mm} \mathrm{Hg}$, a pulmonary artery occlusion pressure (PAOP) $\leq 15 \mathrm{~mm} \mathrm{Hg}$, a pulmonary vascular resistance (PVR) $>3$ Wood units (WU) or $>240$ dynes $/ \mathrm{s} / \mathrm{cm}^{-}$ 5 , and a normal or decreased cardiac output $(\mathrm{CO})^{1}$. Currently, due to the lack of a clear definition of mPAP, PVR and outcome, the term "PH on exercise" is not recommended ${ }^{1}$.

POPH patients meet these criteria with an increased hepatic vein pressure gradient (HVPG), and they can be classified according to the degree of mPAP increase (Table 1). Up to $20 \%$ of patients with portal hypertension and a mPAP between 25 and $35 \mathrm{~mm} \mathrm{Hg}$ harbor a hyperdynamic circulatory state (cardiac output increased) and/or a postcapillary element (increased PAOP) ${ }^{16,35}$.

In patients with portal hypertension, a mPAP $\geq 25$ $\mathrm{mm} \mathrm{Hg}$ and a PAOP $>15 \mathrm{~mm} \mathrm{Hg}$ lead to a diagnostic dilemma. There is no POPH consensus on the usefulness of the transpulmonary pressure gradient $(\mathrm{TPPG})=\mathrm{mPAP}$ - PAOP, in the diagnosis of patients with a reactive or disproportionate postcapillary PH (TPPG $>12 \mathrm{~mm} \mathrm{Hg}$ ) in the context of portal hypertension. The importance of this subtype of $\mathrm{PH}$ is that the histopathological image is similar to that of IPAH patients9. This type of postcapillary PH is seen in patients with left ventricular diastolic dysfunction alone or with concomitant systolic dysfunction ${ }^{30}$, although these associations have not been found in POPH patients ${ }^{11}$.

Patients with portal hypertension, a mPAP $>35 \mathrm{mmHg}$, PAOP $>15 \mathrm{mmHg}$ and PVR below $3 \mathrm{WU}$ or 240 dynes/s/ $\mathrm{cm}^{-5}$ or more, could represent a POPH subgroup since their TPPG is generally above $12 \mathrm{mmHg}^{11,30}$.

\section{Histology and pathophysiology}

Histologically, POPH may be similar to IPAH. In the muscular pulmonary arteries (diameter $<500$ micrometers), the intimal layer may be thickened, with hypertrophy and fibrosis of the mean tier. In situ thrombosis associated with endothelial dysfunction (deficiency in pulmonary endothelial prostacyclin production) ${ }^{12}$, hypercoagulability, the formation of plexiform lesions, necrotizing arteritis and fibrinoid necrosis is also evident ${ }^{23}$. These all increase blood flow resistance through the pulmonary vascular bed ${ }^{10}$. Since this is a rare disease, no study model is yet available to accurately determine its pathogenesis, so no satisfactory pathophysiological explanation for the development of POPH has been established, but the initial stimulus initiates the pathogenic cascade and other factors sustain it. A hyperdynamic circulatory state has been proposed as the first stimulus (increased blood flow of chronic liver disease, characterized by a high cardiac output and subsequent vascular wall shear stress) ${ }^{3}$. It is associated with an imbalance between vasoconstrictor, vasodilator, and tissue 
proliferative substances in the blood such as endothelin-1 (ET-1), interleukin-1, serotonin, glucagon, thromboxane $B 2$, vasoactive intestinal peptide and interleukin- $6^{36,37}$. DuBrock et al. demonstrated that some cytokines such as macrophage inflammatory protein-3 beta, hepatocyte growth factor, macrophage migration inhibitory factor (MIF), platelet-derived growth factor AA, interleukin-17 A, monocyte chemoattractant protein-1, myeloperoxidase, leptin, and growth hormone can be elevated $>1.5$ fold in patients with $\mathrm{POPH}^{38}$. If they are combined with the presence of a shunt that diverts portal blood flow away from the liver thus precluding their inactivation via hepatic metabolism, the resulting injury is perpetuated. Others have suggested that an increased circulation of ET-1, estradiol levels and interleukin 6, is a potential injury promoter or initiator ${ }^{39}$. Some genetic polymorphisms relating to estrogen signaling, cellular growth/apoptosis, and oxidative stress have also been considered and upon genetic analysis, the ENG gene has shown the greatest mutational frequency ${ }^{18,40}$.

\section{Diagnosis}

Many patients may initially present with dyspnea or signs of RH failure ${ }^{7}$, but up to $60 \%$ can be asymptomatic. Even if dyspnea is the first symptom, it can be associated with cirrhosis complications at first and later be associated with syncope, lightheadedness, or chest pain ${ }^{13}$. In the REVEAL study, $31 \%$ of patients referred fatigue, $33 \%$ had edema, and $12 \%$ had abdominal distension as clinical manifestations ${ }^{5}$. Physical examination can detect an accentuated and split second heart sound, a right ventricular heave, right sided S3 gallop and jugular vein distention $^{3,23}$. Although some clinical signs can suggest the diagnosis, TTE and RHC are still needed, especially in symptomatic patients and those being screened for $\mathrm{LT}^{41,42}$. Other recommended tests include a non-encouraged 6-minute walk test (6MWD), pulmonary function tests, arterial blood gases, ventilation/perfusion lung scan and high-resolution computed tomography ${ }^{29}$. Arterial blood gases may show mild to moderate hypoxemia, an increased alveolar-arterial oxygen gradient and decreased carbon dioxide levels ${ }^{3}$. Noninvasive biomarkers have been evaluated, and a MIF $>60 \mathrm{ng} / \mathrm{mL}$ is considered a potential surrogate whereby its area under the curve is 0.77 , it has $92 \%$ sensitivity and $92 \%$ specificity for the diagnosis of $\mathrm{POPH}^{38}$.

In the literature, the term systolic pulmonary artery pressure (SPAP) is frequently used as the main echocardiographic measurement in the context of $\mathrm{PH}$. But there is much data that can be obtained by TTE, including pulmonary regurgitation end-diastolic velocity, $\mathrm{RV} /$ left ventricular ratio, RV outflow tract acceleration time, tricuspid annular plane displacement in systole, $\mathrm{RV}$ isovolumetric relaxation time, RV wall thickness, inferior vena cava (IVC) inspiratory collapse degree ${ }^{14}$, RV performance index, RV tissue doppler index, eccentricity index, $\mathrm{CO}$ and $\mathrm{LV}$ diastolic function, valvular morphology/ function, cardiac defects, and right atrial area ${ }^{3,14}$.

One must consider that echo SPAP is not the same as the echo RV systolic pressure (RVSP) ${ }^{43}$. The latter is calculated with the peak tricuspid regurgitant velocity (TRV) plus the right atrial pressure (RAP): $\mathrm{RVSP}=4 \mathrm{x} \mathrm{RRV}^{2}+\mathrm{RAP}^{44}$. Unfortunately, RAP cannot be directly measured with TTE and it can only be estimated with the inspiratory variation in IVC diameter in a subcostal echo view. The term SPAP can be used instead of RVSP only if a RV outflow tract obstruction is excluded ${ }^{43,44}$.

TRV aids in the decision on who is a RHC candidate. Patients with a TRV $>3.4 \mathrm{~m} / \mathrm{s}$ (PH high-probability) and TRV 2.8-3.4 m/s (PH intermediate probability) plus echo data suggestive of RV pressure overload need to undergo RHC to establish the hemodynamic POPH diagnosis ${ }^{1}$.

In a study of LT candidates, a PSAP $<38 \mathrm{mmHg}$ had a negative predictive value of $100 \%$, a positive predictive value of $41 \%$, a sensitivity of $100 \%$ and a specificity of $93 \%{ }^{41}$. If patients have a PSAP $\geq 50 \mathrm{mmHg}$, a RHC is required, as well as appropriate interpretation of the fundamental pulmonary hemodynamic parameters ${ }^{45}$, since TTE cannot sufficiently discriminate between patients with pulmonary vascular disease (increased PVR) and those with a hyperdynamic flow state (normal or low PVR) ${ }^{3}$. Reports have shown that only $24 \%$ of a UK cohort ${ }^{32}$ and up to $65 \%$ in a UNOS MELD exception group ${ }^{46}$ of patients diagnosed as POPH had a correct diagnosis by RHC. The utility of acute vasoreactivity testing ${ }^{23}$ is to determine which patients would be appropriate candidates for long-term calcium channel blocker (CCB) therapy for the management of PH. Currently, only patients with the idiopathic and anorexigenic forms of $\mathrm{PAH}$ require this test. In the case of POPH patients the use of CCB is risky and not indicated.

Pulmonary hemodynamics in chronic liver disease patients are characterized by a hyperdynamic state associated to a minimal increase in PAOP and increased CO (there is passive distention of compliant arteries and recruitment of upper lung arteries) ${ }^{3}$, but also, to an increase in pulmonary venous volume either directly due to hypervolemia and/or increased pressure resulting from the limitation of pulmonary blood flow to the left atrium (reflected as an increase in PAOP). Finally, there is fixed pulmonary vascular disease due to obliterative changes in the vasculature (true $\mathrm{POPH})^{3}$.

Intrapulmonary vascular dilations (IPVDs) have been reported in up to $59 \%$ of patients, suggesting an overlap between $\mathrm{POPH}$ and the hepatopulmonary syndrome. Their presence can compromise treatment (induce hypoxemia) as well as outcome/survival, especially in the LT setting?. 
Two conclusions can be obtained: first, all POPH patients need a contrast-enhanced TTE and second, further information is needed to corroborate this association.

Aside from the previously described parameters, some reports advocate for the use of a TTPG $>12 \mathrm{mmHg}$ since it can reflect real vascular remodeling ${ }^{45}$, particularly if the PVR and PAOP are elevated (25\% of cases) ${ }^{45}$. However TTPG can suffer variations due to $\mathrm{CO}$ changes, distention and recruitment of pulmonary vessels ${ }^{47}$. In the context of increased PAOP and PVR, the diastolic pulmonary gradient is apparently more reliable in predicting structural vascular changes.

\section{Treatment}

Effective management begins with an early diagnosis and requires surveillance over time ${ }^{18}$ (Figure 2). POPH should be treated according to the patient's functional status, with an escalating regimen of vasodilator therapy ${ }^{5}$. Currently, up to 14 Food and Drug Administration approved therapies can be considered in $\mathrm{POPH}^{48}$, but only $28.5 \%$ of patients receive targeted pre-transplant treatment ${ }^{49}$. In patients with $\mathrm{POPH}$, a delay in initiating medication is associated with an erratic use, resulting in poorer overall survival than in patients with IPAH ( $40 \%$ vs. $67 \%)^{5}$.

\section{General strategies}

The primary intent is to improve the patient's quality of life and provide symptomatic relief, but also other factors must be taken into account. If hypoxemia is present, long-term oxygen therapy should be considered. Annual immunization against influenza and pneumococcus is necessary and pregnancy should be avoided ${ }^{14}$.

There is a definite increased risk of thrombosis due to factors such as venous stasis and right heart enlargement, but this needs to be balanced with the risk of bleeding, since this population characteristically has thrombocytopenia and varices. Anticoagulation should be administered on a caseby-case basis ${ }^{13}$. B-blockers are commonly used in cirrhotic patients, but in patients with a mPAP $\geq 35-40 \mathrm{mmHg}$, their withdrawal should be considered since this strategy can increase cardiac output (CO) as well as exercise capacity. Nonetheless, no formal recommendation has yet to be made ${ }^{50}$.

Cirrhotic patients tend to have volume overload, so a standard combination of furosemide and spironolactone (ratio of $40 \mathrm{mg}$ and $100 \mathrm{mg}$, respectively) can be considered, but they have to be used with caution

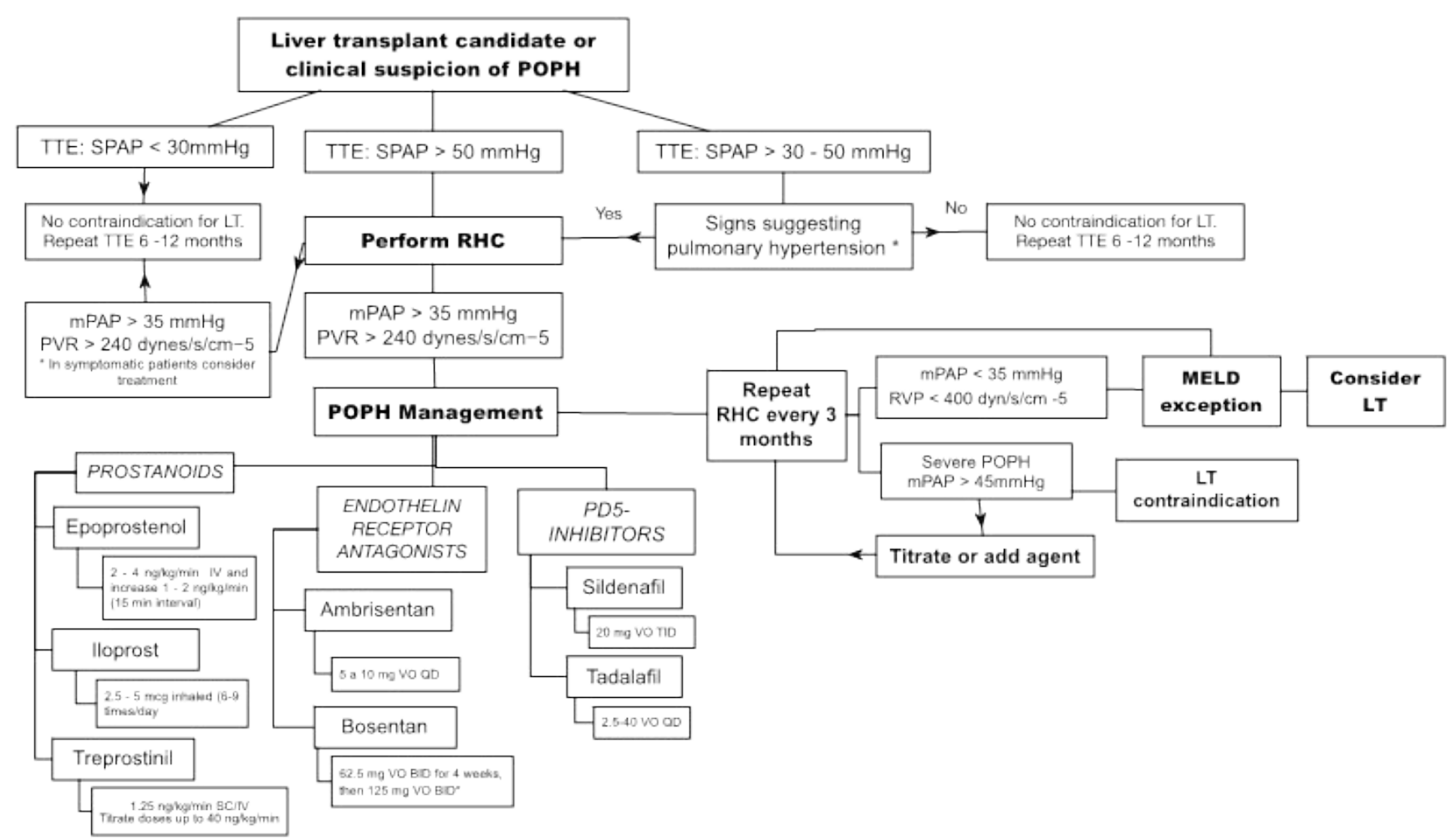

POPH: portopulmonary hypertension. SPAP: systolic pulmonary arterial pressure. mPAP: mean pulmonary arterial pressure. PVR: pulmonary vascular resistance. LT: liver transplant. RHC: right heart catheterization. TTE: transthoracic echocardiogram. PD-5: phosphodiesterase type 5. *Signs suggesting pulmonary hypertension: right ventricle/left ventricle baseline ratio $>1.0$, Flattening of the interventricular septum (left ventricular eccentricity index $>1.1$ in systole and/or diastole), Right ventricular outflow Doppler acceleration time $<105 \mathrm{mseg}$, Early diastolic pulmonary regurgitation velocity $>2.2 \mathrm{~m} / \mathrm{sec}$, pulmonary arterial diameter $>25 \mathrm{~mm}$, Inferior cava diameter $>21 \mathrm{~mm}$ with an inspiratory collapse $<50 \%$ and right atrial area $>18 \mathrm{~cm}^{2}$.

Figure 2. Diagnosis and management of pulmonary hypertension. 
since they can decrease $\mathrm{CO}$ by diminishing the RV preload ${ }^{51}$. The use of CCB can be dangerous since they promote fluid retention, reduce $\mathrm{RV}$ function and lead to an increase in portal pressure $\mathrm{e}^{14}$. Transjugular intrahepatic portosystemic shunt is not recommended since it can worsen $\mathrm{POPH}^{23}$.

\section{Pharmacological management}

Patients with POPH have always been excluded from prospective $\mathrm{POPH}$ trials so their management has been inferred from other forms of $\mathrm{PAH}^{49}$. Prostacyclin analogues, endothelin receptor antagonists, and phosphodiesterase-5 Inhibitors are therapeutic options. At the moment, most of the efficacy data has resulted from cohort studies, and new data is expected shortly on ambrisentan (Portopulm - NCT01224210), macitentan (PORTICO - NCT02382016), and sildenafil (RePo1 - NCT01517854) ${ }^{52}$.

\section{Prostacyclin Analogues}

This drug category possesses vasodilation, antithrombotic and antiproliferative properties ${ }^{14}$; epoprostenol, treprostinil, and iloprost are some examples. Reported side effects are flushing, headache, jaw pain, diarrhea, nausea, musculoskeletal aches and pain ${ }^{14}$.

Epoprostenol, a metabolite of arachidonic acid has been successfully used as a preparatory step to LT. It needs to be administered with an intravenous (IV) pump (with the ensuing risk of bloodstream infections) since its halflife is $2-3 \min ^{53}$. Hemodynamic improvement has been reported. In a cohort of 36 patients with moderate and severe POPH, followed for a median of 15.4 months, mPAP, PVR, and CO improved in 19 patients and two recovered sufficiently to be considered for LT $^{54}$. Treatment can also provide a benefit in functional capacity ${ }^{49,55}$ and IV use can increase 5 -year survival to $71 \%$. Other observed changes are improvement in brain natriuretic peptide and human atrial natriuretic peptide levels ${ }^{23}$. Careful follow-up is needed since epoprostenol can worsen hepatic function and cause clinical deterioration; it may also cause progressive splenomegaly ${ }^{23}$.

An advantage of iloprost is its route of access since it can be nebulized. It has a half-life of $20-30 \mathrm{~min}$, and can increase exercise tolerance as well as survival to $77 \%, 62 \%$ and $46 \%$ at 1-,3- and 5-years respectively ${ }^{14}$. No interaction is expected with HCV treatment drugs ${ }^{56}$.

Treprostinil is considered long-acting since it has a half-life of 4.5 hours $^{53}$. It can be administered via the oral, subcutaneous or IV route ${ }^{57}$. It has been used in the pre-LT setting with favorable results, and during the perioperative period no hemodynamic instability, reperfusion syndrome, worsening of $\mathrm{PH}$ or the need of additional treatment were observed $^{53}$. Like iloprost, it can be combined with sildenafil in LT candidates ${ }^{58}$ who may even be switched to oral sildenafil 2-3 months after $\mathrm{LT}^{53}$. Of note, its effectiveness is dosage-related and infections associated with the presence of a catheter are always a risk. Final results from the treprostinil trial (NCT01028651) that included 13 patients, are shortly expected. To date, the preliminary report revealed that 12 patients did not reach the primary endpoint (mPAP below $35 \mathrm{mmHg}$ and PVR under 3 Wood units at 24 weeks $)^{59}$.

\section{Endothelin Receptor Antagonists (ERA)}

ERA selectively or non-selectively block the ability of ET-1 to bind with the A or B endothelin receptor in endothelial and arterial smooth muscle, thus inhibiting vasoconstriction. Bosentan and ambrisentan are examples.

Bosentan can improve exercise capacity and hemodynamic variables in $\mathrm{POPH}$, independently of the liver disease severity. Reports show that after 5 months, PVR decrease $31 \%$ and the cardiac index increases $39 \%{ }^{14}$. Other studies have reported a 3-year survival rate of $89 \%$.

Bosentan has three circulating metabolites resulting from cytochrome $\mathrm{P} 450$ activity and it is primarily eliminated by hepatic metabolism, possibly involving the organic anion transport protein (OATP ${ }^{60}$. In vitro and in vivo evidence shows extensive hepatic metabolism by CYP2C9 and CYP3A, so concomitant administration of CYP2C9 inhibitors such as fluconazole, amiodarone, itraconazole, amprenavir, erythromycin or diltiazem could increase plasma bosentan concentrations ${ }^{60}$. It can also increase liver transaminases (three times above the upper limit of normal), but this may resolve with drug dose reduction or discontinuation ${ }^{58}$. Contraceptives may not be reliable when coadministered $^{60}$. In the case of HCV treatment drugs, elbasvir/grazoprevir is contraindicated, ombitasvir/ paritaprevir/ritonavir + dasabuvir is not recommended nor is the velpatasvir/sofosbuvir combination. Potential interaction has been reported with daclatasvir, but the Ledipasvir/Sofosbuvir combination does not appear to interact. For more information on interactions with $\mathrm{HCV}$ drugs, http://www.hep-druginteractions.org/checker can be reviewed ${ }^{61}$. Glyburide is contraindicated with the use of bosentan.

Ambrisentan is an oral selective ERA with a longer half-life - up to 15-hours - and minimal renal elimination. It is primarily metabolized by uridine $5^{\prime}$-diphosphate glucuronosyltransferases (UGTs) and to a lesser extent, by CYP3A and CYP2C19; it is not recommended in severe hepatic impairment ${ }^{60}$. It improves mPAP, PVR, and CO, it has few hepatic side effects ${ }^{58}$ and it can be used when bosentan is not tolerated. No dose adjustment has been recommended if coadministered with ketoconazole, warfarin, digoxin, contraceptives, omeprazole or rifampicin ${ }^{60}$. In the case of HCV treatment drugs, potential interaction is expected with elbasvir/grazoprevir and ombitasvir/paritaprevir/ ritonavir + dasabuvir. Daclatasvir, Velpatasvir/Sofosbuvir, 
Ledipasvir/Sofosbuvir do not appear to interact. For further information on interactions with HCV drugs, http://www. hep-druginteractions.org/checker can be reviewed ${ }^{61}$.

Macitentan is a newer molecule with sustained receptor binding and increased tissue penetration. In PAH (SERAPHIN), it has shown to decrease morbidity but not mortality ${ }^{48}$. Results from the PORTICO trial are expected (24-week study to evaluate the efficacy and safety of macitentan, $10 \mathrm{mg}$ once daily). In the case of HCV treatment drugs, potential interaction is expected with ombitasvir/paritaprevir/ritonavir + dasabuvir. With daclatasvir, elbasvir/grazoprevir, Velpatasvir/Sofosbuvir and Ledipasvir/Sofosbuvir no interactions are to be expected $^{56}$. In patients with POPH awaiting LT, ambrisentan or macitentan are preferable options to bosentan ${ }^{29}$.

\section{Phosphodiesterase-5 Inhibitors}

These drugs prevent the metabolism of cyclic guanosine monophosphate which mediates the vascular effects of nitric oxygen (NO) and the consequent reduction in pulmonary arterial pressure. Sildenafil is a well-known agent and has demonstrated improvement in functional class, exercise capacity (6MWD), it decreases PVR, mPAP, BNP, and increases CO at a dose of $50 \mathrm{mg}, 3$ times a day. In combination with iloprost ${ }^{55,62}$, the improvement was sustained over 12 months. Long-term use has been recommended, and in a report by Boniface et al., sildenafil was used two years in a patient with severe POPH; it was well tolerated, with improvement in functional class, dyspnea and $6 \mathrm{MWD}^{62}$ with no liver toxicity or impact on PTH. Further data is needed on the long-term use of sildenafil.

Other categories such as sildenafil - bosentan (in this presentation, sildenafil may increase bosentan systemic exposure by up to $50 \%$, so adequate monitoring is recommended $^{60}$ ), bosentan and tadalafil (no significant changes in bosentan were reported with coadministration ${ }^{60}$ ), and ambrisentan (no dose adjustment is needed in dual therapy ${ }^{60}$ ) can also be used. When all oral therapies are analyzed, they can improve hemodynamic and clinical parameters, leading to a response in liver transplantation eligibility criteria (MPAP below $35 \mathrm{mmHg}$ or $35 \leq \mathrm{mPAP}<50 \mathrm{mmHg}$ with PVR under 250 dynes/s/ $\mathrm{cm}^{-5}$ ) in $53 \%$ of patients ${ }^{55}$. However, combinations are preferred especially in patients with severe pulmonary hypertension or in need of an urgent LT, since oral drugs may not be sufficient ${ }^{29}$. If it is used in a patient on HCV drug therapy, the concomitant use of ombitasvir/paritaprevir/ ritonavir + dasabuvir is contraindicated.

\section{Soluble guanylate cyclase stimulator}

Riociguat, a soluble guanylate cyclase stimulator, can increase cyclic guanosine monophosphate production and lead to vasodilatation. It has been shown to lead to a sustained 4-year improvement in exercise and functional capacity in patients with PAH (drop-out rate of $47 \%)^{63}$, but no data is available on its long-term use in POPH. Reported adverse events are nasopharyngitis, peripheral edema and hemoptysis (that can be fatal, and in cirrhotic patients, caution must be advised). In the PATENT study, 13 patients received $2.5 \mathrm{mg}$, three times a day ( 2 in placebo, 11 with riociguat) but no sub-analysis was performed ${ }^{1,14}$.

\section{Liver transplantation}

LT has been considered the cure of end-stage liver disease. Even if POPH has been taken into account as an "indication" for LT, this is still controversial and an adequate evaluation is needed since fatal outcomes have been reported after LT (in the immediate/early postoperative period) in cases of severe $\mathrm{POPH}^{32,64}$. Markedly, in those with a diagnosis established in the operating room.

Waitlist candidates with POPH exception points have a higher risk of death than patients with no exception points. In a report by DuBrok et al., up to $23.2 \%$ of patients have been withdrawn after a median time on the waitlist of 344 days. Among these patients, $7 \%$ died while on the waitlist, $14.2 \%$ were withdrawn due to clinical deterioration and $2.1 \%$ died during surgery ${ }^{65}$; Savale et al. reported a mortality rate of $29 \%$ in patients without access to $\mathrm{LT}^{29}$. Predictors of waitlist mortality (waitlist withdrawal due to death or clinical deterioration) have been sought and to date, age (HR 1.04, 95\% CI 1.00-1.08, P=0.0499), initial native MELD score (> 12) (HR 1.11, 95\% CI 1.05-1.17, $\mathrm{P}<0.001)$, and initial PVR $\left(\geq 240\right.$ dynes $/ \mathrm{s} / \mathrm{cm}^{-5}$ ) (HR 1.12 per 100 dynes $/ \mathrm{s} / \mathrm{cm}^{-5}$, 95\% CI 1.02-1.23, P=0.02) have been associated with the waitlist mortality. These data raise concern on the actual UNOS policy since these factors do not impact post-transplant mortality ${ }^{65}$.

Mild POPH has minimal perioperative risks ${ }^{27}$, but moderate disease leads to different outcomes. In a report of patients with mPAP between 34 and $60 \mathrm{mmHg}, 5$ of 12 died within one month post-LT ${ }^{66}$. Also, a mPAP above 35 $\mathrm{mmHg}$ has been associated with a greater risk of death, prolonged post-LT ventilation, ICU readmission, and a longer hospital stay ${ }^{49,67,68}$. Once appropriate management has been implemented, and normalization of RV size/function pre-LT, a safe LT can be performed in $50 \%$ of cases ${ }^{49}$; it is associated with a $64 \% 3$-years survival ${ }^{46}$. The routine use of pharmacotherapy, careful patient selection and decreasing mPAP $\leq 35 \mathrm{mmHg}$ is required ${ }^{42,66}$. Used treatments have included sildenafil, epoprostenol, and bosentan ${ }^{27}$. In a UK cohort, 8 of 30 POPH patients were treated with sildenafil, ambrisentan, and sildenafil or epoprostenol preoperatively, and after LT, 3 patients required iloprost. After a 5-year follow-up, five of the eight patients were still alive (in the mild category treated with sildenafil, one died within 6 months, 
and one lived; 4 patients with moderate POPH that received treatment were alive; 2 in the severe POPH category, but that were pre-operatively optimized, also died ${ }^{32}$.

When a patient has a mPAP > $50 \mathrm{mmHg}$ and/or PVR > 800 dynes $/ \mathrm{s} / \mathrm{cm}^{-5}$, the patient should not be considered a LT candidate $^{23,49}$. Although recent reports of improved survival are available, death can be associated with fulminant RV failure, and an associated mortality rate of $42 \%$ at 9-months and $71 \%$ at 3-years makes it unacceptable ${ }^{32}$. In cases where LT is to be performed in patients with severe POPH (young, in good clinical condition and without severe right ventricular dysfunction or high PVR), with a positive response to vasodilator therapy, the use of inhaled nitric oxide and intravenous epoprostenol should be considered $^{69}$, as well as right ventricular function evaluation. Khaderi et al. have reported the outcome of 7 patients with severe POPH. All received vasodilator therapy (6 with IV epoprostenol, one with oral sildenafil) with IV or inhaled epoprostenol during the perioperative period. The survival rate was $86.7 \%$ at 7.8 years $^{70}$.

Indications for LT are hepatic decompensation (ascites, hepatic encephalopathy, variceal bleeding) and a MELD $\geq$ 15. Patients with mild POPH will not be granted exception MELD points because to acquire them, patients under treatment must fulfill certain criteria (Table 2) ${ }^{71}$. The aim of this policy is to perform the LT before irreversible changes relating to POPH develop ${ }^{69}$. However, UNOS does not provide criteria pertaining to satisfactory RV function. In spite of the UNOS criteria, other scenarios should be considered since patients with a mPAP > $35 \mathrm{mmHg}$ can have normalization of PVR and RV function with treatment and they are still not considered for exception points ${ }^{71}$.

During surgery, three critical moments need to be considered. Anesthetic induction, the anhepatic phase, and reperfusion ${ }^{14}$. Significant changes in pulmonary hemodynamics after reperfusion may develop ${ }^{10}$, and an increase of $5-18 \%$ in $\mathrm{CO}$ (more than $15 \mathrm{~L} / \mathrm{min}$ ) could cause additional strain on a pre-existing strained $\mathrm{RV}^{72}$. This phase is critical since up to $30 \%$ of LT can develop the reperfusion syndrome, resulting in a rise in PA pressures that can precipitate RV failure and subsequent graft congestion ${ }^{10}$. Aside from a prolonged surgery, poor early graft function, primary graft dysfunction, or death due to hemodynamic causes (myocardial infarction or cardiac arrhythmias) may also complicate the LT course. Management in this instance can be further supported with the use of inhaled NO, IV prostacyclin, milrinone or extracorporeal membrane oxygenation (ECMO) ${ }^{73,74}$

Since sufficient predictors are unavailable for normalization of post-LT hemodynamics, IV fluids need to be balanced and in some cases restricted; if renal function has deteriorated, hemodialysis must be considered. The key to management is to avoid right ventricular failure from

\section{Criteria}

1. Moderate to severe POPH diagnosed by $\mathrm{RHC}$ :
a. $\mathrm{mPAP} \geq 35 \mathrm{mmHg}$
b. PVR $>240$ dynes $/ \mathrm{sec} / \mathrm{cm}-5$ (3 WU)
c. $P O A P<15 \mathrm{mmHg}$

2. Improvement with $\mathrm{PAH}$-specific therapy (12 weeks):
a. $\mathrm{mPAP}<35 \mathrm{mmHg}$
b. PVR $<400$ dynes/sec/cm-5 ( $<5$ Wood units) and
c. Satisfactory RV function*

3. MELD exception updates every three months and 2 points would be added.

Exception points for Liver transplantation in Portopulmonary hypertension.

mPAP: Mean pulmonary arterial pressure; PVR: pulmonary vascular resistance; PAOP: Pulmonary arterial occlusion pressures. POAP: Pulmonary artery occlusion pressure. RHC: Right heart catheterization. RV: Right ventricle

(Modified from Ann Hepatol 2014;13:719-21)

Table 2: Model for End-Stage Liver Disease (MELD) exception points in Portopulmonary hypertension.

acutely elevated pulmonary artery pressure or a sudden increase in right ventricular preload ${ }^{66}$. Pharmacological treatment (alone or in combination, such as prostanoids, nitric oxide, and sildenafil or epoprostenol IV + nitric oxide, inhaled iloprost + nitric oxide, sildenafil + nitric oxide) can be continued during hospitalization and RHC needs to be performed before weaning can be considered ${ }^{71}$. In some instances, a gradual switch from prostanoids to sildenafil can be made, and since no clear guidelines are available, careful hemodynamic monitoring is crucial. In some cases, this change can be made over a 2 to 3 month period $^{53}$. Some reports suggest that the first 6-months after LT are characterized by instability, but after this period, improvement in cardiopulmonary hemodynamics is possible with near-normalization or normalization of the mPAP and $\mathrm{PVR}^{29}$. RHC can be considered on a case-tocase basis. Precaution is recommended when tacrolimus is used since it can induce hypertension and further increase the afterload and deteriorate left ventricular diastolic dysfunction ${ }^{68}$. The choice of POPH-targeted therapy should be based on parameters such as PH severity, severity of pre-transplant liver disease and the potential interactions with immunosuppressive therapy ${ }^{29}$.

In the case of sildenafil and calcineurin inhibitors such as tacrolimus, interaction might exist, because both drugs are metabolized via the P4503A4 cytochrome pathway. In a study by Christ et al., sildenafil pharmacokinetics in renal transplant recipients was evaluated: the concomitant administration of these drugs led to a $44 \%$ greater sildenafil maximal plasma concentration and a $90 \%$ greater AUC. Also, the elimination half-time for sildenafil was prolonged (4.7 hours) $)^{75,76}$. Since blood pressure decreases have been reported, a starting dose of $25 \mathrm{mg}$ sildenafil should be considered with adjustment of antihypertensive drugs if they are concomitantly administered ${ }^{75,77}$. 
Since bosentan is metabolized by CYP2C9 and CYP3A, its interaction with calcineurin inhibitors is relevant. If cyclosporine is also administered, on the first day of concomitant administration, a 30 -fold increase in bosentan was observed, reaching a steady state in up to 7 days ${ }^{60}$. At this time, the coadministration of bosentan and cyclosporine is contraindicated ${ }^{60}$.

In the case of ambrisentan, a 58\% increase in its steadystate has been observed if administered with cyclosporine, and it could also be associated with cyclosporine-induced inhibition of hepatic OATP-mediated uptake ${ }^{60}$. The current recommendation istousea once a day $5 \mathrm{mgdose}$. In the case of tacrolimus, no adjustments are necessary since no changes in the steady-state of ambrisentan have been reported ${ }^{60}$. Mycophenolate mofetil is another immunosuppressant option, it has a UGT enzyme metabolism and when coadministered, no significant changes have been reported, so no dose adjustment is required ${ }^{60}$.

Since LT can cure a life-threatening process in a distant organ, how to accurately select these patients and how to prioritize them is still a research issue. Combined lung and LT is an option for patients with coexisting disease such as cystic fibrosis and Alfa 1-proteinase inhibitor deficiency. In cases of combined liver - lung transplant with POPH, 3-year survival is $62 \%$ and a 5 -year survival of $49 \%$ has been reported $^{23,27}$; this therapeutic strategy may not be routinely required in cases of mild to moderate $\mathrm{POPH}$.

In conclusion, $\mathrm{POPH}$ is a type of pulmonary hypertension present in patients with cirrhosis. Despite the fact that pharmacological therapy is available, careful patient selection, intensive pre-operative optimization, and expert perioperative care are needed to further survival benefits.

\section{Acknowledgment}

I would like to thank the Consejo Nacional de Ciencia $y$ Tecnologia (CONACYT) for their financial support throughout completion of the Master's Degree.

\section{Conflict of interest}

None of the authors have conflicts of interest to disclose.

\section{References}

1. Galiè N, Humbert M, Vachiery JL, et al. 2015 ESC/ERS Guidelines for the diagnosis and treatment of pulmonary hypertension: The Joint Task Force for the Diagnosis and Treatment of Pulmonary Hypertension of the European Society of Cardiology (ESC) and the European Respiratory Society (ERS): Endorsed by: Association for European Paediatric and Congenital Cardiology (AEPC), International Society for Heart and Lung Transplantation (ISHLT). Eur Heart. J 2016; 37: 67-119.

2. Simonneau G, Gatzoulis MA, Adatia I, et al. Updated clinical classification of pulmonary hypertension. J Am Coll Cardiol. 2013; 62: D34-41.

3. Porres-Aguilar M, Zuckerman MJ, Figueroa Casas JB, et al. Portopulmonary hypertension: state of the art. Ann Hepatol. 2008; 7: 321-330.
4. Montaño-Loza A, Meza Junco J. [Pathogenesis of portal hypertension]. Rev Investig Clin Organo Hosp Enfermedades Nutr. 2005; 57: 596607.

5. Krowka MJ, Miller DP, Barst RJ, et al. Portopulmonary hypertension: a report from the US-based REVEAL Registry. Chest. 2012; 141: 906915.

6. Hoeper MM, Bogaard HJ, Condliffe R, et al. Definitions and Diagnosis of Pulmonary Hypertension. J Am Coll Cardiol. 2013; 62: D42-D50.

7. Fonseca AXC, Valois FM, Ferreira EVM, et al. Intrapulmonary vascular dilatations are common in portopulmonary hypertension and may be associated with decreased survival. Liver Transpl. 2016; 22: 562-563.

8. Porres Aguilar M, Altamirano JT, Torre Delgadillo A, et al. Portopulmonary hypertension and hepatopulmonary syndrome a clinician-oriented overview. Eur Respir Rev. 2012; 21: 223-233.

9. Rodríguez Roisin R, Krowka MJ, Hervé P, et al. Pulmonary Hepatic vascular Disorders (PHD). Eur Respir J. 2004; 24: 861-880.

10. Krowka MJ, Fallon MB, Kawut SM, et al. International Liver Transplant Society Practice Guidelines: Diagnosis and Management of Hepatopulmonary Syndrome and Portopulmonary Hypertension. Transplantation. 2016; 100: 1440-1452.

11. Krowka MJ, Swanson KL, Frantz RP, et al. Portopulmonary hypertension Results from a 10-year screening algorithm. Hepatology. 2006; 44: 1502-1510.

12. Zardi EM, Zardi DM, Giorgi C, et al. Portopulmonary hypertension and hepatorenal syndrome two faces of the same coin. Eur J Intern Med Epub ahead of print June. 2017. DOI: 10.1016/j.ejim.2017.05.028.

13. Cosarderelioglu C, Cosar AM, Gurakar M, et al. Portopulmonary hypertension and liver transplant recent review of the literature. Exp Clin Transpl. 2016; 14: 113-120.

14. Rodríguez Almendros N, Toapanta Yanchapaxi LN, Aguirre Valadez J, et al. [Portopulmonar hypertension Updated review]. Arch Cardiol Mex. Epub ahead of print 13 December 2016. DOI: 10.1016/j. acmx.2016.11.002.

15. Humbert M, Sitbon 0 , Chaouat A, et al. Pulmonary arterial hypertension in France: results from a national registry. Am J Respir Crit Care Med. 2006; 173: 1023-1030.

16. Herve P, Le Pavec J, Sztrymf B, et al. Pulmonary vascular abnormalities in cirrhosis. Best Pract Res Clin Gastroenterol. 2007; 21: 141-159.

17. Ridaura Sanz C, Mejía Hernández C, López Corella E. Portopulmonary hypertension in children a study in pediatric autopsies. Arch Med Res. 2009; 40: 635-639.

18. Fussner LA, Krowka MJ. Current Approach to the Diagnosis and Management of Portopulmonary Hypertension. Curr Gastroenterol Rep. 18. Epub ahead of print June 2016. DOI: 10.1007/s11894-0160504-2.

19. Sithamparanathan S, Nair A, Thirugnanasothy L, et al. Survival in portopulmonary hypertension Outcomes of the United Kingdom National Pulmonary Arterial Hypertension Registry. J Heart Lung Transplant. 2017; 36: 770-779.

20. Kawut SM, Krowka MJ, Trotter JF, et al. Clinical risk factors for portopulmonary hypertension. Hepatol Baltim Md. 2008; 48: 196203.

21. Le Pavec J, Souza R, Herve P, et al. Portopulmonary hypertension: survival and prognostic factors. Am J Respir Crit Care Med. 2008; 178: 637-643

22. Segraves JM, Cartin-Ceba R, Leise MD, et al. The Relationship Between Portopulmonary Hypertension and Splenectomy Mayo Clinic Experience and Literature Review. Hepatol Res Off J Jpn Soc Hepatol. Epub ahead of print 1 July 2017. DOI: 10.1111/hepr.12930. 
23. Saleemi S, Idrees M. Saudi Guidelines on the Diagnosis and Treatment of Pulmonary Hypertension: Portopulmonary hypertension. Ann Thorac Med. 2014; 9: 42.

24. Talwalkar JA, Swanson KL, Krowka MJ, et al. Prevalence of spontaneous portosystemic shunts in patients with portopulmonary hypertension and effect on treatment. Gastroenterology. 2011; 141: 1673-1679.

25. Colle IO, Moreau R, Godinho E, et al. Diagnosis of portopulmonary hypertension in candidates for liver transplantation a prospective study. Hepatol Baltim Md. 2003; 37: 401-409.

26. Ramsay MA, Simpson BR, Nguyen AT, et al. Severe pulmonary hypertension in liver transplant candidates. Liver Transplant Surg Off Publ Am Assoc Study Liver Dis Int Liver Transplant Soc. 1997; 3: 494-500.

27. Mancuso L. Management of portopulmonary hypertension: New perspectives. World J Gastroenterol. 2013; 19: 8252.

28. DeMartino ES, Cartin-Ceba R, Findlay JY, et al. Frequency and Outcomes of Patients With Increased Mean Pulmonary Artery Pressure at the Time of Liver Transplantation: Transplantation. 2017; 101: 101-106.

29. Savale L, Sattler C, Coilly A, et al. Long-term outcome in liver transplantation candidates with portopulmonary hypertension: Savale et al. Hepatology. 2017; 65: 1683-1692.

30. Swanson KL, Wiesner RH, Nyberg SL, et al. Survival in portopulmonary hypertension: Mayo Clinic experience categorized by treatment subgroups. Am J Transplant Off J Am Soc Transplant Am Soc Transpl Surg. 2008; 8: 2445-2453.

31. Kawut SM, Taichman DB, Ahya VN, et al. Hemodynamics and survival of patients with portopulmonary hypertension. Liver Transplant Off Publ Am Assoc Study Liver Dis Int Liver Transplant Soc. 2005; 11: 1107-1111.

32. Verma S, Hand F, Armstrong MJ, et al. Portopulmonary hypertension: Still an appropriate consideration for liver transplantation. Liver Transpl. 2016; 22: 1637-1642.

33. Safdar Z, Bartolome S, Sussman N. Portopulmonary hypertension: An update. Liver Transpl. 2012; 18: 881-891.

34. Cartin-Ceba R, Krowka MJ. Portopulmonary hypertension. Clin Liver Dis. 2014; 18: 421-438.

35. Galiè N, Hoeper MM, Humbert M, et al. Guidelines for the diagnosis and treatment of pulmonary hypertension: the Task Force for the Diagnosis and Treatment of Pulmonary Hypertension of the European Society of Cardiology (ESC) and the European Respiratory Society (ERS), endorsed by the International Society of Heart and Lung Transplantation (ISHLT). Eur Heart J. 2009; 30: 2493-2537.

36. Huffmyer JL, Nemergut EC. Respiratory dysfunction and pulmonary disease in cirrhosis and other hepatic disorders. Respir Care. 2007; 52: 1030-1036.

37. Wong F. Portopulmonary hypertension in cirrhosis: the pathogenetic challenge. Gut. 2005; 54: 309.

38. DuBrock HM, Rodriguez-Lopez JM, LeVarge BL, et al. Macrophage Migration Inhibitory Factor as a Novel Biomarker of Portopulmonary Hypertension. Pulm Circ. 2016; 6: 498-507.

39. Pellicelli AM, Barbaro G, Puoti C, et al. Plasma cytokines and portopulmonary hypertension in patients with cirrhosis waiting for orthotopic liver transplantation. Angiology. 2010; 61: 802-806.

40. Pousada G, Baloira A, Valverde D. Cribado mutacional en genes relacionados con la hipertensión portopulmonar: análisis de 6 casos. Med Clínica. 2017; 148: 310-313.

41. Raevens S, Colle I, Reyntjens K, et al. Echocardiography for the detection of portopulmonary hypertension in liver transplant candidates: An analysis of cutoff values: Echocardiography in Liver Transplantation. Liver Transpl. 2013; 19: 602-610.
42. Murray KF, Carithers RL, AASLD. AASLD practice guidelines: Evaluation of the patient for liver transplantation. Hepatol Baltim Md. 2005; 41: 1407-1432.

43. Rudski LG, Lai WW, Afilalo J, et al. Guidelines for the Echocardiographic Assessment of the Right Heart in Adults: A Report from the American Society of Echocardiography. J Am Soc Echocardiogr. 2010; 23: 685713.

44. Garg A, Armstrong WF. Echocardiography in liver transplant candidates. JACC Cardiovasc Imaging. 2013; 6: 105-119.

45. Porres-Aguilar M, Mukherjee D. Cardiopulmonary hemodynamics for accurate diagnosis of portopulmonary hypertension: a redefinition to consider. Hepatol Baltim Md. 2015; 61: 733-734.

46. Goldberg DS, Batra S, Sahay S, et al. MELD Exceptions for Portopulmonary Hypertension: Current Policy and Future Implementation: Transplantation in POPH. Am J Transplant. 2014; 14: 2081-2087.

47. Naeije R, Vachiery JL, Yerly P, et al. The transpulmonary pressure gradient for the diagnosis of pulmonary vascular disease. Eur Respir J. 2013; 41: 217-223.

48. DuBrock HM, Channick RN, Krowka MJ. What's new in the treatment of portopulmonary hypertension. Expert Rev Gastroenterol Hepatol. 2015; 9: 983-992.

49. Krowka MJ, Heimbach JK. Portopulmonary hypertension and liver transplantation: A duo in question. Liver Transpl. 2016; 22: 16331634.

50. Provencher S, Herve $\mathrm{P}$, Jais $\mathrm{X}$, et al. Deleterious effects of betablockers on exercise capacity and hemodynamics in patients with portopulmonary hypertension. Gastroenterology. 2006; 130: 120126.

51. Pericleous M, Sarnowski A, Moore A, et al. The clinical management of abdominal ascites, spontaneous bacterial peritonitis and hepatorenal syndrome: a review of current guidelines and recommendations. Eur J Gastroenterol Hepatol. 2016; 28: e10-18.

52. Search of: portopulmonary hypertension - List Results - ClinicalTrials.govhttps://clinicaltrials.gov/cresults?cond=portopulmonary+hypertension\&term $=\&$ cntry $1=\&$ state $1=\&$ SearchAll=Search + all + studies\&recrs $=$ (accessed 8 July 2017)

53. Sakai T, Planinsic RM, Mathier MA, et al. Initial experience using continuous intravenous treprostinil to manage pulmonary arterial hypertension in patients with end-stage liver disease: Treprostinil for pulmonary hypertension in ESLD. Transpl Int. 2009; 22: 554-561.

54. Fix OK, Bass NM, De Marco T, et al. Long-term follow-up of portopulmonary hypertension: effect of treatment with epoprostenol. Liver Transplant Off Publ Am Assoc Study Liver Dis Int Liver Transplant Soc. 2007; 13: 875-885.

55. Legros L, Chabanne C, Camus C, et al. Oral pulmonary vasoactive drugs achieve hemodynamic eligibility for liver transplantation in portopulmonary hypertension. Dig Liver Dis. 2017; 49: 301-307.

56. Liverpool HEP Interactions. Liverpool HEP interactionshttp://www. hep-druginteractions.org/ (accessed 9 July 2017).

57. Hollatz TJ, Musat A, Westphal S, et al. Treatment with sildenafil and treprostinil allows successful liver transplantation of patients with moderate to severe portopulmonary hypertension. Liver Transpl. 2012; 18: 686-695.

58. Lv Y, Han G, Fan D. Portopulmonary hypertension. Scand J Gastroenterol. 2016; 51: 795-806.

59. A Study to Assess the Safety and Efficacy of Treprostinil to Facilitate Liver Transplantation in Patients With Portopulmonary Hypertension - Study Results - ClinicalTrials.govhttps://clinicaltrials.gov/ ct2/show/results/NCT01028651? cond=Portopulmonary+Hypertension\&amp;rank=4\&amp;sect=X01256\#all (accessed 10 July 2017). 
60. Venitz J, Zack J, Gillies H, et al. Clinical Pharmacokinetics and DrugDrug Interactions of Endothelin Receptor Antagonists in Pulmonary Arterial Hypertension. J Clin Pharmacol. 2012; 52: 1784-1805.

61. Liverpool HEP Interactions. Liverpool HEP interactionshttp://www. hep-druginteractions.org/checker (accessed 9 July 2017).

62. Boniface S, Gaubert JY, Blanc A, et al. Functional improvement in a patient with cirrhosis and portopulmonary hypertension treated by sildenafil for 2 years. Respir Med CME. 2010; 3: 263-266.

63. Halank M, Hoeper MM, Ghofrani HA, et al. Riociguat for pulmonary arterial hypertension and chronic thromboembolic pulmonary hypertension: Results from a phase II long-term extension study. Respir Med. 2017; 128: 50-56.

64. De Wolf AM, Gasior T, Kang Y. Pulmonary hypertension in a patient undergoing liver transplantation. Transplant Proc. 1991; 23: 2000 2001.

65. DuBrock HM, Goldberg DS, Sussman NL, et al. Predictors of Waitlist Mortality in Portopulmonary Hypertension: Transplantation. 2017; 101: 1609-1615.

66. European Association for the Study of the Liver. Electronic address: easloffice@easloffice.eu. EASL Clinical Practice Guidelines: Liver transplantation. J Hepatol. 2016; 64: 433-485.

67. Krowka MJ, Wiesner RH, Heimbach JK. Pulmonary contraindications, indications and MELD exceptions for liver transplantation: a contemporary view and look forward. J Hepatol. 2013; 59: 367-374.

68. Rajaram P, Parekh A, Fisher M, et al. Comparison of Post Liver Transplantation Outcomes in Portopulmonary Hypertension and Pulmonary Venous Hypertension: A Single-Center Experience. Transplant Proc. 2017; 49: 338-343.
69. Bozbas SS. Portopulmonary hypertension in liver transplant candidates. World J Gastroenterol. 2016; 22: 2024.

70. Khaderi S, Khan R, Safdar Z, et al. Long-term follow-up of portopulmonary hypertension patients after liver transplantation: Portopulmonary Hypertension. Liver Transpl. 2014; 20: 724-727.

71. Porres Aguilar M, Bartolome SD, Duarte Rojo A. MELD exception for liver transplantation in portopulmonary hypertension: current implementation and future considerations. Ann Hepatol. 2014; 13: 719-721.

72. Ramsay M. Portopulmonary hypertension and right heart failure in patients with cirrhosis. Curr Opin Anaesthesiol. 2010; 23: 145-150.

73. Golbin JM, Krowka MJ. Portopulmonary hypertension. Clin Chest Med. 2007; 28: 203-218, ix.

74. Fijalkowska A, Kurzyna M, Torbicki A, et al. Serum N-terminal brain natriuretic peptide as a prognostic parameter in patients with pulmonary hypertension. Chest. 2006; 129: 1313-1321.

75. Christ B, Brockmeier D, Hauck EW, et al. Interactions of sildenafil and tacrolimus in men with erectile dysfunction after kidney transplantation. Urology. 2001; 58: 589-593.

76. Cofan F, Gutierrez R, Beardo P, et al. Interaction between sildenafil and calcineurin inhibitors in renal transplant recipients with erectile dysfunction. Nefrol Publicacion Of Soc Espanola Nefrol. 2002; 22: 470-476.

77. Christ B, Brockmeier D, Hauck EW, et al. Investigation on interaction between tacrolimus and sildenafil in kidney-transplanted patients with erectile dysfunction. Int J Clin Pharmacol Ther. 2004; 42: 149156. 